\title{
A novel modification of the Endorectal Advancement Flap for complex anal fistulas: surgical technique and outcomes
}

Hassan Al-Turaihi ( $\square$ hassan.turaihi@gmail.com )

UH Cleveland Medical Center https://orcid.org/0000-0001-8418-7869

Blears Elizabeth

Allegheny Health Network

Sugumar Kavin

UH Cleveland Medical Center

Deshmukh Maya

Yale University School of Medicine

Deshmukh Ganesh

Beaumont Hospital

Research article

Keywords: Fistula in Ano, Endorectal Flap, Fecal incontinence

Posted Date: August 4th, 2020

DOI: https://doi.org/10.21203/rs.3.rs-43719/v1

License: (c) (i) This work is licensed under a Creative Commons Attribution 4.0 International License. Read Full License 


\section{Abstract}

Background Fistula-in-ano is a common problem encountered by surgeons which can be classified as either simple or complex. Complex fistulas (CF) cause higher morbidity and are much more challenging to treat. Although numerous treatment options are available for $\mathrm{CF}$, none are proven to be $100 \%$ effective. The endorectal advancement flap (EAF) procedure was developed as an alternative to conventional surgical treatments for CF. Herein, we describe a novel modification of the EAF procedure along with surgical outcomes in terms of recurrence, fecal incontinence and factors associated with flap failure.

Methods A retrospective review of patients with complex fistula-in-ano who underwent EAF between 2004-2019 was done. The conventional EAF procedure was modified by performing transverse imbrication of the internal sphincter over the internal fistula opening. The incidence of post-operative recurrence and fecal incontinence were calculated from chart documentation at the last available date of follow-up. Also, the association between various clinical and demographic factors and post-operative flap failure were calculated using Chi-squared test and student's t-test or Mann-Whitney $U$ test with statistical significance at alpha $<0.05$.

Results With a median follow-up of 6.6 months (range: 1.6-84.5 months), 99 patients with CFs underwent a modified EAF. Of these, 93\% (92/99) had a successful procedure, 7\% (7/99) experienced recurrence and $3 \%(3 / 99)$ experienced postoperative fecal incontinence. Systemic steroid or immunomodulatory therapy use $(p=0.001)$ and patients with diagnosed inflammatory bowel disease $(p<0.0001)$ were associated with increased rate of flap failure.

Conclusion EAF with transverse imbrication of the internal opening using interrupted, absorbable suture is an effective technique to treat complex or recurrent anal fistulas. It is associated with a low risk of recurrence $(7 \%)$ and fecal incontinence (3\%) and a valid treatment option for complex fistula-in-ano.

\section{Background}

Perianal fistulas are one of the most common conditions treated by colorectal and general surgeons. ${ }^{1,2}$ Although anal fistulas are not life-threatening, they result in debilitating pain and soiling, which negatively affect quality of life. ${ }^{3,4}$ In most instances, history of perianal abscess precedes fistula-in-ano. ${ }^{1,2,5}$ Although, $50-70 \%$ of patients resolve with surgical drainage, $30-50 \%$ progress to develop perianal fistula. This corroborates the theory of cryptoglandular origin as the most common cause of fistula-in-ano. ${ }^{1,2,5}$ Since the risk of progression to fistula-in-ano is higher with certain underlying etiologies, addressing the underlying cause is important to preventing recurrence. ${ }^{1,2}$

Simple fistulas are low-lying with low risk of fecal incontinence as they do not involve the external anal sphincter. ${ }^{5}$ They can be treated by either fistulotomy or fistulectomy, both with high success rates. On the contrary, complex fistulas are located higher in the anal canal and can involve the anal sphincter complex. ${ }^{5}$ They can communicate with adjacent organs, such as the vagina, and often develop in 
conjunction with inflammatory bowel disease. ${ }^{6}$ They can also be due to iatrogenic injury post-surgery. Surgical procedures developed to treat complex fistulas include ligation of the fistula tract (LIFT), ${ }^{9}$ videoassisted anal fistula treatment (VAAFT), ${ }^{10,11}$ and endorectal advancement flap (EAF). ${ }^{12,13}$ Non-surgical options include fibrin glue plugs and stem cell paste. Even though non-surgical options have low risk of fecal incontinence, they have lower success rate compared to surgery ${ }^{7,8}$. At present, there is no ideal treatment strategy for complex fistulas. ${ }^{1,2}$

EAF is one of the most common procedures performed for complex fistulas. It was first reported by Nobel (1902) for rectovaginal fistulas that commonly resulted from obstetric trauma. It was later modified using a flap of rectal tissue to close the tract between the source of the fistula and its opening. ${ }^{12,14,15}$ Flaps can be tongue-shaped, rhomboid, or elliptical and can include the rectal mucosa alone, or extend deeper to include the submucosa, partial layers of the internal anal sphincter or the entire thickness of the internal anal sphincter. ${ }^{1,2}$ Traditionally, the opening of the fistula within the rectum is either left open to heal by secondary intention or closed with simple, interrupted, or figure-of-eight sutures. ${ }^{12,14,15}$ In addition to the flap, the fistula tract can be treated with curette or coring out. ${ }^{1,2}$ Although technically complex, the advantage of the EAF is that the sphincter complex is left intact, and thus, has a lower risk for fecal incontinence when compared to other options. ${ }^{1,2}$ After study for over a century, EAF has an accepted recurrence rate of $7-48 \%$ with a risk of fecal incontinence of $15-20 \% .{ }^{1,2}$ However, the optimal thickness of the flap and technique for complex fistulas is unknown.

Herein, we aim to describe a novel modification of the EAF procedure along with surgical outcomes in terms of recurrence and fecal incontinence post-surgery. We also examine the factors associated with flap failure.

\section{Methods}

A retrospective chart review of patients diagnosed with complex rectal or anal fistulas who underwent an EAF procedure by the Principal Investigator between January 2004 and February 2019 was done. This study was approved by the Institutional Review Board under Protocol \# 2019-233.

\section{Inclusion and Exclusion Criteria:}

Patients who presented with complex rectal or anal fistulas and underwent EAF placement were included. A complex rectal or anal fistula was defined as one or more of the following: (i) fistula tract that involve at least the proximal two-thirds of the external anal sphincter (ii) involvement of any nearby organ, (iii) etiology associated with a high risk of recurrence (i.e., pelvic radiation, Crohn's disease, etc.), (iv) recurrence after previous fistula surgery. Complex fistulas were diagnosed and initially assessed by physical examination. If fistula tract or anatomy was unclear, MRI was done to confirm the presence of complex fistula-in-ano.

\section{Data Collection:}


Patient demographic information including age, sex, race, body mass index (BMI), number and type of previous perianal surgeries, history of smoking, systemic steroid use, immunomodulator or immunosuppressive use, Inflammatory Bowel Disease (Crohn's, Ulcerative Colitis (UC) or indeterminant colitis), Chronic Obstructive Pulmonary Disease, Congestive Heart Failure, Coronary Artery Disease, Type II Diabetes Mellitus, Hypertension, and Chronic Kidney Disease were recorded if listed as a diagnosis within the patient's chart. Immunomodulator or immunosuppressive use was defined as those who before or at the time of surgery received the current FDA approved agents for the treatment of Crohn's or UC (including, mercaptopurine, azathioprine, infliximab, or any novel monoclonal antibodies), or chemotherapy for alternative cancer, or immunosuppression for a history of solid organ transplantation. The etiology of fistula-in-ano including cryptoglandular, Crohn's disease, UC, post-obstetric fistula, radiation-induced, carcinoma, or Hidradenitis Suppurativa was noted. Additional information regarding the surgical procedure was noted including date of surgery, date of subsequent follow-up visits and date of last follow-up, presence of recurrence of symptoms post-surgery, and subsequent surgical interventions (such as diversion, fistulectomy or repeat EAF). The presence of fecal incontinence, before and after surgery, was recorded based on a non-validated questionnaire.

\section{Outcomes:}

Primary outcomes were fistula recurrence and new-onset fecal incontinence after EAF surgery. The symptoms were assessed, and the operative site was examined by the surgical team at the same hospital at 1-2 weeks post-surgery and then every 3 months until complete healing. Recurrence was defined as "the presence of an abscess or purulent drainage from the primary fistula area after at least 6 weeks of healing from EAF". Fecal incontinence was defined as "difficulty controlling stools (soiling) or flatus during follow-up as described by the patient."1,2

\section{Endorectal Advancement Flap: Technical details}

\section{Preoperative and intraoperative patient preparation:}

All patients received full bowel preparation prior to surgery. On the day of the surgery, a fleet or saline enema was given to the patient based on tolerability. All procedures were performed in the outpatient setting under spinal or general anesthesia. Patients that had fistulas with an anterior lying internal opening were positioned in a prone-jack-knife position, whereas those with a posterior internal opening were placed in a lithotomy position.

\section{Description of the surgical technique:}

Initial exposure of the surgical field is provided using a Park's anal retractor, which is later exchanged for a large or medium-sized Sawyer or Hill-Ferguson retractor to decrease tension on the lateral edges during flap closure. Since local anesthetic injection around the future flap site could potentially compromise flap 
perfusion, local anesthetic is not administered. The rectal mucosa is dissected using needle-tip electrocautery, ensuring a flap base that is three times wider than the apex of the flap (Figure 2A \& 2B). Once the flap is created, the internal opening is closed by imbricating the internal sphincter using multiple transverse interrupted 2-0 Vicryl sutures (Figure 2A \& 2C). This modification not only serves to close the internal sphincter opening, but it also decreases tension on the flap during the closure. The flap is secured over the center of the defect by suturing the inferior edge of the flap with multiple interrupted 3-0 Vicryl sutures to the internal sphincter and anoderm distally. Compared to running sutures, interrupted suture placement is believed to be essential in allowing drainage of fluid and blood from underneath the flap that would otherwise collect and impair healing. The lateral edges of the flap are then closed with running 3-0 Vicryl suture, with lateral bites that measured less than 3mm (Figure 2D).

All external fistula openings and granulation tissue are debrided in a core-out fashion, and the fistula tract(s) are excised to the border of the external sphincter muscle (Figure 3A, 3B \&3C). Post-operatively, patients are instructed to avoid strenuous activity and provided with non-narcotic analgesia for 7 days. Patients are followed-up in the clinic at 1-2 weeks postoperatively and approximately every 3 months thereafter until complete healing. Fiber supplements are provided to maintain regular bowel movements and avoid constipation during post-operative healing.

\section{Statistical Analysis:}

Continuous variables were reported as median with interquartile range (IQR). Categorical variables were represented as frequency with percentages. Data was analyzed for normality using the Shapiro-Wilki's test. Student's t-test was used to analyze normally distributed data, and Mann-Whitney $U$ tests were used to analyze data that was not normally distributed. Categorical variables were compared using Pearson chi-squared test. Statistical analysis was performed using StataSE software (StataCorp. 2019. Stata Statistical Software: Release 16. College Station, TX: StataCorp LLC), and statistical significance was defined as $\mathrm{P}<0.05$. Figures were created using Adobe Illustrator version 24.0.1

\section{Results}

Records from 111 patients between 2004-2019 that underwent EAF for complex fistulas were reviewed. Twelve patients were excluded from analysis because their underlying etiology required a fundamentally different treatment pathway than patients presenting with complex fistulas, including diverticulitis $(\mathrm{N}=5)$ and squamous cell carcinoma $(\mathrm{N}=1)$. Seven patients were lost to follow-up and were excluded. Therefore, the final cohort consisted of a total of 99 patients (Figure 1).

\section{Patient demographics:}

The median age at presentation was 46 years (IQR: $37-55$ years), 55\% (54/99) were male, and median Body Mass Index (BMI) was $29 \mathrm{~kg} / \mathrm{m}^{2}$ (IQR: 22-36). Caucasians comprised $78 \%$ of the cohort followed by African Americans (13\%), Asian Americans (7.5\%), and other minorities (1.5\%). 
Thirty-nine patients (39.4\%) underwent anorectal surgery for fistula-in-ano prior to EAF, and the median number of prior fistula procedures was 2 (IQR: 1-2). These previous procedures included fistulotomy/fistulectomy $(33 \%, 33 / 99)$, LIFT $(3 \%, 3 / 99)$, Henley drainage procedure for horseshoe abscess $(1 \%, 1 / 99)$, and $\operatorname{EAF}(2 / 99,2 \%)$. The three patients that underwent prior LIFT increased the technical difficulty while performing EAF, due to scarring of the internal anal sphincter and accumulation of granulation tissue, as described by operative notes. The common etiologies of fistula-inano included cryptoglandular disease $(77 \%, 76 / 99)$, Crohn's disease $(16 \%, 16 / 99)$, UC $(2 \%, 2 / 99)$, radiation injury $(2 \%, 2 / 99)$, indeterminate colitis $(1 \%, 1 / 99)$, obstetric injury $(1 \%, 1 / 99)$, and Hidradenitis Suppurativa $(1 \%, 1 / 99)$, as shown in (Table 1$)$.

A total of $102 \mathrm{EAF}$ procedures were performed among 99 patients, with 3 patients receiving repeat EAF for fistula recurrence. Of the 99 patients that underwent EAF, 93\% (92/99) had successful healing, and 7\% (7/99) experienced recurrence. On performing subgroup analysis, we found that patients without a history of inflammatory bowel disease (IBD) had successful healing of $98 \%(78 / 80)$, compared to patients with IBD $(73.6 \%, 14 / 19)$. Of those that had successful healing, $80 \%$ (74/92) experienced immediate healing within 1-2 weeks postoperatively and $20 \%$ (18/92) experienced healing by the final postoperative visit without repeat interventions. Those that experienced delayed healing reported prolonged pain or drainage that resolved with local wound care. Among the 7 patients that experienced recurrence, 1 patient (14\%) was managed conservatively with wound care but remained symptomatic until last follow-up. This patient decided to consult elsewhere following the final visit. Six patients $(6 / 7,86 \%)$ required repeat surgery that resulted in complete resolution of their symptoms, this included fistulectomy or debridement $(\mathrm{N}=3)$, repeat $\operatorname{EAF}(\mathrm{N}=3)$.

There was a statistically significant correlation between patients who had a history of systemic steroid use and fistula recurrence after EAF $(P=0.0001)$. Also, patients with diagnosed Inflammatory bowel disease had lower success rate $(P<0.0001)$. There was no significant association between age, race, gender, or BMI, history of smoking, chronic comorbidities, and recurrence following surgery $(P>0.05$, Table 2).

At first postoperative visit (1-2 weeks), $3 \%$ (3/99) of patients presented with new-onset fecal incontinence. These patients were followed-up for a median of 6 months (IQR: 3-24 months). Of the patients who developed new-onset fecal incontinence, one patient experienced complete resolution of symptoms without additional interventions, while two patients continued to have mild symptoms that were controlled with stool bulking agents.

\section{Discussion}

This study reports a large cohort of patients with complex anal rectal fistulas undergoing EAF by using transverse imbrication of the internal sphincter over the internal fistula opening. This modification securely closes the opening of the fistula while eliminating tension from the flap, which is an improvement over the standard EAF approach. Our cohort consisted of patients with various etiologies of 
complex fistulas such as cryptoglandular disease, Crohn's disease, UC, radiation, and obstetric trauma. ${ }^{1,2}$ Among this diverse population, there was a recurrence-free rate of $93 \%$, with a median duration of followup of 6 months, making this study one of the largest, most successful and longest that is reported in the literature. ${ }^{1,2,16}$

Many studies discuss the limited descriptive data on complex fistula populations who undergo EAF. ${ }^{1,2}$ At present, there is still no clear definition of a "typical" patient with this pathology, and it is unclear if the results from this series can be applied to other populations. Traditional EAF is known to have a recurrence rate of $7-48 \%$ in patients with complex fistulas. ${ }^{1,2}$

Other treatment options available to treat fistulas in ano include video assisted anal fistula surgery which has an overall recurrence rate of $15.8 \%,{ }^{17}$ Ligation of fistula tract (LIFT); a sphincter sparing technique that has gained popularity recently due to high success rates of $76 \%$ for complex anal fistula. ${ }^{18}$ Also, worth mentioning is the Fistula Laser Closure (FiLAC) which another sphincter saving procedure, has an overall success rate of $69 \%$ for fistula-in-ano. ${ }^{19}$ Our modification of EAF demonstrates a much lower recurrence rate of $7 \%$.

Additionally, the rate of postoperative fecal incontinence (3\%) is low compared to other studies (15$20 \%)^{1,2}$ Patients who developed fecal incontinence after EAF were seen to have significant scarring at the time of surgery, as per operative records. More severe scarring likely resulted in more extensive dissection and, therefore, increased risk of sphincter involvement. Further study of these patients would be required to see how much this new-onset fecal incontinence was impacting their lives, and if it was an improvement over their original fistula symptoms.

Moreover, further research is needed to compare this modified EAF procedure to traditional approaches, such as a traditional figure-of-8 closure or no suture closure, or those involving flaps with partial or fullthickness internal sphincter components. These efforts might better delineate which modifications of the EAF procedure that would result in a higher success rate. Furthermore, comparisons between various EAF modifications and other sphincter-sparing procedures, such as fibrin glue, ${ }^{20}$ stem cell pastes, ${ }^{8}$ and more invasive surgical procedures such as LIFT and video-assisted anal fistula treatment (VAAFT) ${ }^{10,11}$ are needed to optimize treatment planning for those at high risk of incontinences.

\section{Limitations}

Due to the retrospective design, this study is limited in accuracy by potential selection and confounding since all variables for a patient's condition could not be accounted for. Patients were studied from a single center, thus limiting the generalizability and reproducibility of the results. Moreover, as with any study of a surgical technique, there are risks of minor changes in technique depending on the surgeon's judgment for what is best for each individual patient. However, since patients were managed with the 
similar technique and treatment algorithm, it adds reliability to our results. The patient population studied was diverse in terms of the underlying disease process and previous history of perianal procedures for similar symptoms. In terms of outcomes, quality-of-life or functional recovery was not studied, and there was no objective assessment of continence.

\section{Conclusion}

The study describes the surgical technique of the modified EAF procedure along with outcomes. This procedure shows promising outcomes and seems to be a valid treatment option of complex fistula-inano. Additional controlled studies are needed to compare this modification with the traditional EAF technique, and with other treatment types for complex fistula-in-ano.

\section{List Of Abbreviations}

BMI: Body mass index, CF: Complex fistulas, EAF: Endorectal advancement flap, FiLAC: Fistula Laser Closure, IQR: interquartile range, LIFT: Ligation of intersphincteric tract, UC: Ulcerative colitis, VAAFT: video-assisted anal fistula treatment

\section{Declarations}

\section{Ethics approval and consent to participate:}

This study was approved on October 7, 2019 by the Internal Review Board of Oakland University- William Beaumont Hospital Health Care System, Royal Oak, MI under protocol \# 2019-233, Category 4

\section{Consent for publication:}

Not applicable.

\section{Availability of data and materials:}

The datasets used and/or analyzed during the current study are available from the corresponding author on reasonable request. Availability of data was obtained after IRB approval under protocol \# 2019-233.

\section{Competing interest:}

The authors declare that they have no competing interests

\section{Funding:}


Funding was not required for the production of this study, nor the manuscript preparation. All authors therefore have no declarations of funding sources

\section{Authors' contributions:}

Both Hassan Al-Turaihi, MD and Blears E., MD contributed equally to this work; both provided Idea, manuscript writing, data collection and drafting.

KS, MD: Provided data analysis

MD, MD: Provided tables and figures

GD, MD: Provided manuscript drafting.

All authors read and approved the final manuscript.Acknowledgement: Not applicable

\section{Authors information:}

Hassan Al-Turaihi: Case Western Reserve University, Department of Colon and Rectal Surgery, 11100 Euclid Ave. Lakeside 7, Cleveland, Ohio, 44106

Kavin Sugumar: Case Western Reserve University, Department of Colon and Rectal Surgery, 11100 Euclid Ave. Lakeside 7, Cleveland, Ohio, 44106

Elizabeth Blears: Allegheny Health Network, Department of Colorectal Surgery, 320 East North Ave, Pittsburgh, PA, 15212

Maya Deshmukh: Yale University School of Medicine, 333 Cedar Street, New Haven, CT 06510

Ganesh Deshmukh: Oakland University William Beaumont School of Medicine, Department of Colon and Rectal Surgery, 3601 W 13 mile Rd, Royal Oak, MI 48073

\section{References}

1. Balciscueta Z, Uribe N, Balciscueta I, Andreu-Ballester JC, García-Granero E. Rectal advancement flap for the treatment of complex cryptoglandular anal fistulas: a systematic review and metaanalysis. Int J Colorectal Dis. 2017;32(5):599-609. doi:10.1007/s00384-017-2779-7

2. Göttgens KWA, Smeets RR, Stassen LPS, Beets G, Breukink SO. Systematic review and metaanalysis of surgical interventions for high cryptoglandular perianal fistula. Int J Colorectal Dis. 2015;30(5):583-593. doi:10.1007/s00384-014-2091-8

3. Jayarajah U, Wickramasinghe DP, Samarasekera DN. Anal incontinence and quality of life following operative treatment of simple cryptoglandular fistula-in-ano: a prospective study. BMC Res Notes. 
2017;10(1):572. doi:10.1186/s13104-017-2895-z

4. Visscher AP, Schuur D, Roos R, Van der Mijnsbrugge GJH, Meijerink WJHJ, Felt-Bersma RJF. Longterm Follow-up After Surgery for Simple and Complex Cryptoglandular Fistulas. Dis Colon Rectum. 2015;58(5):533-539. doi:10.1097/DCR.0000000000000352

5. Parks AG, Gordon PH, Hardcastle JD. A classification of fistula-in-ano. Br J Surg. 1976;63(1):1-12. doi:10.1002/bjs.1800630102

6. Lewis RT, Maron DJ. Anorectal Crohn's Disease. Surg Clin North Am. 2010;90(1):83-97. doi:10.1016/j.suc.2009.09.004

7. Christoforidis D, Pieh MC, Madoff RD, Mellgren AF. Treatment of Transsphincteric Anal Fistulas by Endorectal Advancement Flap or Collagen Fistula Plug. Dis Colon Rectum. 2009;52(1):18-22. doi:10.1007/DCR.0b013e31819756ac

8. Herreros MD, Garcia-Arranz M, Guadalajara H, De-La-Quintana P, Garcia-Olmo D. Autologous Expanded Adipose-Derived Stem Cells for the Treatment of Complex Cryptoglandular Perianal Fistulas. Dis Colon Rectum. 2012;55(7):762-772. doi:10.1097/DCR.0b013e318255364a

9. Stellingwerf ME, van Praag EM, Tozer PJ, Bemelman WA, Buskens CJ. Systematic review and metaanalysis of endorectal advancement flap and ligation of the intersphincteric fistula tract for cryptoglandular and Crohn's high perianal fistulas. BJS Open. 2019;3(3):231-241. doi:10.1002/bjs5.50129

10. Meinero P, Mori L. Video-assisted anal fistula treatment (VAAFT): a novel sphincter-saving procedure for treating complex anal fistulas. Tech Coloproctol. 2011;15(4):417-422. doi:10.1007/s10151-0110769-2

11. Schwandner O. Video-assisted anal fistula treatment (VAAFT) combined with advancement flap repair in Crohn's disease. Tech Coloproctol. 2013;17(2):221-225. doi:10.1007/s10151-012-0921-7

12. Hilsabeck JR. Transanal advancement of the anterior rectal wall for vaginal fistulas involving the lower rectum. Dis Colon Rectum. 1980;23(4):236-241. doi:10.1007/BF02587089

13. Dudukgian $\mathrm{H}$, Abcarian $\mathrm{H}$. Why do we have so much trouble treating anal fistula? World $\mathrm{J}$ Gastroenterol. 2011;17(28):3292-3296. doi:10.3748/wjg.v17.i28.3292

14. ELTING AW. THE TREATMENT OF FISTULA IN ANO. Ann Surg. 1912;56(5):726-752. doi:10.1097/00000658-191211000-00010

15. Aguilar PS, Plasencia G, Hardy TG, Hartmann RF, Stewart WRC. Mucosal advancement in the treatment of anal fistula. Dis Colon Rectum. 1985;28(7):496-498. doi:10.1007/BF02554093

16. Lee C-L, Lu J, Lim T-Z, et al. Long-term outcome following advancement flaps for high anal fistulas in an Asian population: a single institution's experience. Int J Colorectal Dis. 2015;30(3):409-412. doi:10.1007/s00384-014-2100-y

17. Emile SH, Elfeki H, Shalaby M, Sakr A. A Systematic review and meta-analysis of the efficacy and safety of video-assisted anal fistula treatment (VAAFT). Surg Endosc. 2018 Apr;32(4):2084-2093. doi: 10.1007/s00464-017-5905-2. Epub 2017 Oct19. PubMed PMID: 29052068. 
18. Emile SH, Khan SM, Adejumo A, Koroye O. Ligation of intersphincteric fistula tract (LIFT) in treatment of anal fistula: An updated systematic review, meta-analysis, and meta-regression of the predictors of failure. Surgery. 2020 Feb;167(2):484-492. doi: 10.1016/j.surg.2019.09.012. Epub 2019 Oct 21. PubMed PMID: 31648932.

19. Elfeki, H., Shalaby, M., Emile, S.H. et al. A systematic review and meta-analysis of the safety and efficacy of fistula laser closure. Tech Coloproctol 24, 265-274 (2020). https://doi.org/10.1007/s10151-020-02165-1

20. Adams T, Yang J, Kondylis LA, Kondylis PD. Long-Term Outlook after Successful Fibrin Glue Ablation of Cryptoglandular Transsphincteric Fistula-in-Ano. Dis Colon Rectum. 2008;51(10):14881490. doi:10.1007/s10350-008-9405-2

\section{Tables}

Table 1: Patient Demographics 


\begin{tabular}{|c|c|}
\hline Parameter & Median with interquartile range or n (\%) \\
\hline Age, years & $46(37-55)$ \\
\hline \multicolumn{2}{|l|}{ Gender } \\
\hline Male & $54 / 99(55 \%)$ \\
\hline Female & $45 / 99(45 \%)$ \\
\hline \multicolumn{2}{|l|}{ Race } \\
\hline White & $64 / 82(78 \%)$ \\
\hline Black & $11 / 82(13 \%)$ \\
\hline Asian & $6 / 82(7.5 \%)$ \\
\hline Other & $1 / 82(1.5 \%)$ \\
\hline BMI, $\mathrm{kg} / \mathrm{m} 2$ & $29(22-36)$ \\
\hline Follow-up period & 6.6 months (3-24 months) \\
\hline Incontinence present before surgery & $5 / 99(5 \%)$ \\
\hline History of previous surgeries & $91 / 99(92 \%)$ \\
\hline Previous fistula repair & $39 / 99(39.4 \%)$ \\
\hline \multicolumn{2}{|c|}{ Previous Perianal Surgeries (\% patients who underwent a given procedure previously) } \\
\hline Fistulectomy with or without debridement & $33 / 99(33 \%)$ \\
\hline Ligation of Inter-sphincteric Tract (LIFT) & $3 / 99(3 \%)$ \\
\hline Henley drainage procedure & $1 / 99(1 \%)$ \\
\hline Redo-advancement (previous) & $2 / 99(2 \%)$ \\
\hline Number of previous procedures & $2(1-2)$ \\
\hline \multicolumn{2}{|l|}{ Underlying Diagnosis } \\
\hline Cryptoglandular disease & 76/99 (77\%) \\
\hline Crohn's Disease & $16 / 99(16 \%)$ \\
\hline Ulcerative Colitis & $2 / 99(2 \%)$ \\
\hline Radiation Injury & $2 / 99(2 \%)$ \\
\hline Indeterminate colitis (IBD) & $1 / 99(1 \%)$ \\
\hline Obstetric Injury & $1 / 99(1 \%)$ \\
\hline Hidradenitis Suppurativa & $1 / 99(1 \%)$ \\
\hline \multicolumn{2}{|l|}{ Co-morbidities } \\
\hline Systemic immunomodulator, steroid or & $13 / 99(13 \%)$ \\
\hline Active Smoker/ Former Smoker & $13 / 99(14 \%), 5 / 99$ (5.5\%) \\
\hline Diabetes Mellitus -Type 2 & $12 / 99(12 \%)$ \\
\hline Chronic Obstructive Pulmonary Disease & $5 / 99(5 \%)$ \\
\hline Congestive Heart Failure & $7 / 99(7 \%)$ \\
\hline Coronary Artery Disease & $9 / 99(9 \%)$ \\
\hline Hypertension & $32 / 99(32 \%)$ \\
\hline Chronic kidney disease & $1 / 99(1 \%)$ \\
\hline
\end{tabular}

Table 2: Factors associated with Success vs Recurrence after Endoadvancement Flap 


\begin{tabular}{|c|c|c|c|}
\hline Parameter & $\begin{array}{l}\text { Initial Successful EAF } \\
(\mathrm{N}=92)\end{array}$ & $\begin{array}{l}\text { Recurrence } \\
(\mathrm{N}=7)\end{array}$ & P-value \\
\hline Age (years) $^{+}$ & $47(15-77)$ & $38(25-68)$ & 0.42 \\
\hline \multicolumn{4}{|l|}{ Gender } \\
\hline Male & $48 / 92(52 \%)$ & $6 / 15(85 \%)$ & \\
\hline Female & $44 / 92(48 \%)$ & $1 / 15(15 \%)$ & 0.08 \\
\hline \multicolumn{4}{|l|}{ Race } \\
\hline White & $58 / 76(76.3 \%)$ & $4 / 6(68 \%)$ & \multirow[t]{4}{*}{0.61} \\
\hline Black & $11 / 76(14.5 \%)$ & $1 / 6(16 \%)$ & \\
\hline Asian & $6 / 76(7.9 \%)$ & $1 / 6(16 \%)$ & \\
\hline Other & $1 / 76(1.3 \%)$ & $0 / 6(0 \%)$ & \\
\hline BMI (median, IQR) $\left.\mathrm{kg} / \mathrm{m}^{2}\right)^{+}$ & $29(25-32)$ & $33(18-35)$ & 0.15 \\
\hline Systemic immunomodulator, steroid or & & & \\
\hline chemotherapy use & 9/92 (9\%) & $4 / 7(57 \%)$ & $0.0001 *$ \\
\hline Active Smoker or former Smoker & $16 / 91(17.6 \%)$ & $2 / 7(28.6 \%)$ & 0.46 \\
\hline Diabetes Mellitus Type 2 & $11 / 92(12 \%)$ & $1 / 7(14 \%)$ & 0.1 \\
\hline Chronic Obstructive Pulmonary Disease & $5 / 92(5.4 \%)$ & $0 / 7(0 \%)$ & 0.52 \\
\hline Congestive Heart Failure & $6 / 92(6.5 \%)$ & $1 / 7(14.3 \%)$ & 0.44 \\
\hline Coronary Artery Disease & $8 / 92(8.7 \%)$ & $1 / 7(14.3 \%)$ & 0.62 \\
\hline Hypertension & $29 / 92(31.5 \%)$ & $3 / 7(42 \%)$ & 0.53 \\
\hline Inflammatory bowel disease & $14 / 92(15 \%)$ & $5 / 7(71.4 \%)$ & $<0.0001 *$ \\
\hline Total \# prior procedures ${ }^{+}$ & $2(1-2)$ & $2(2-3)$ & 0.62 \\
\hline Required diverting stoma & $3 / 92(3.2 \%)$ & $0 / 7(0 \%)$ & 0.62 \\
\hline
\end{tabular}

+Median with interquartile range

*Statistically significant $(\mathrm{P}<0.05)$

\section{Figures}




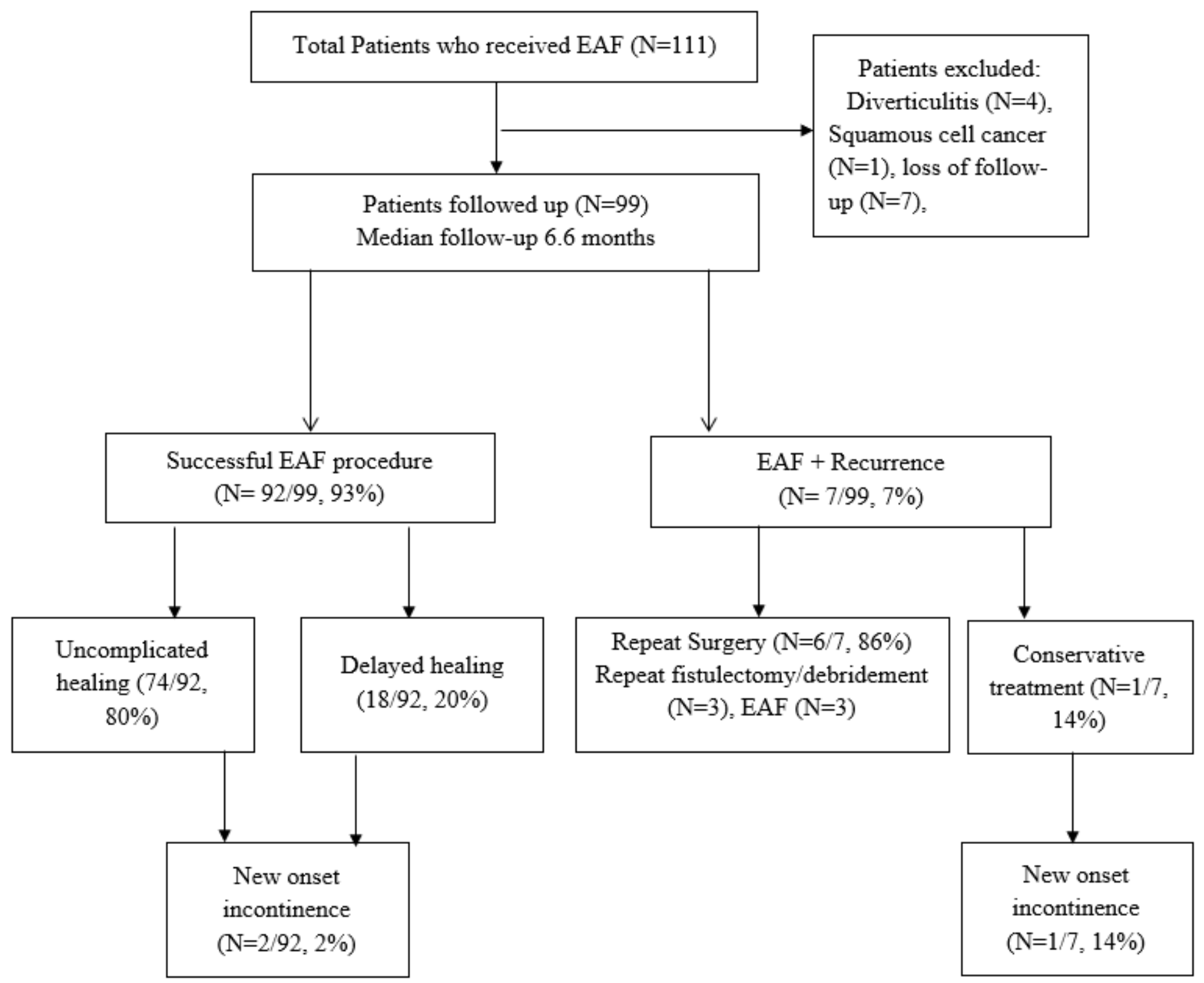

Figure 1

Study flow diagram 


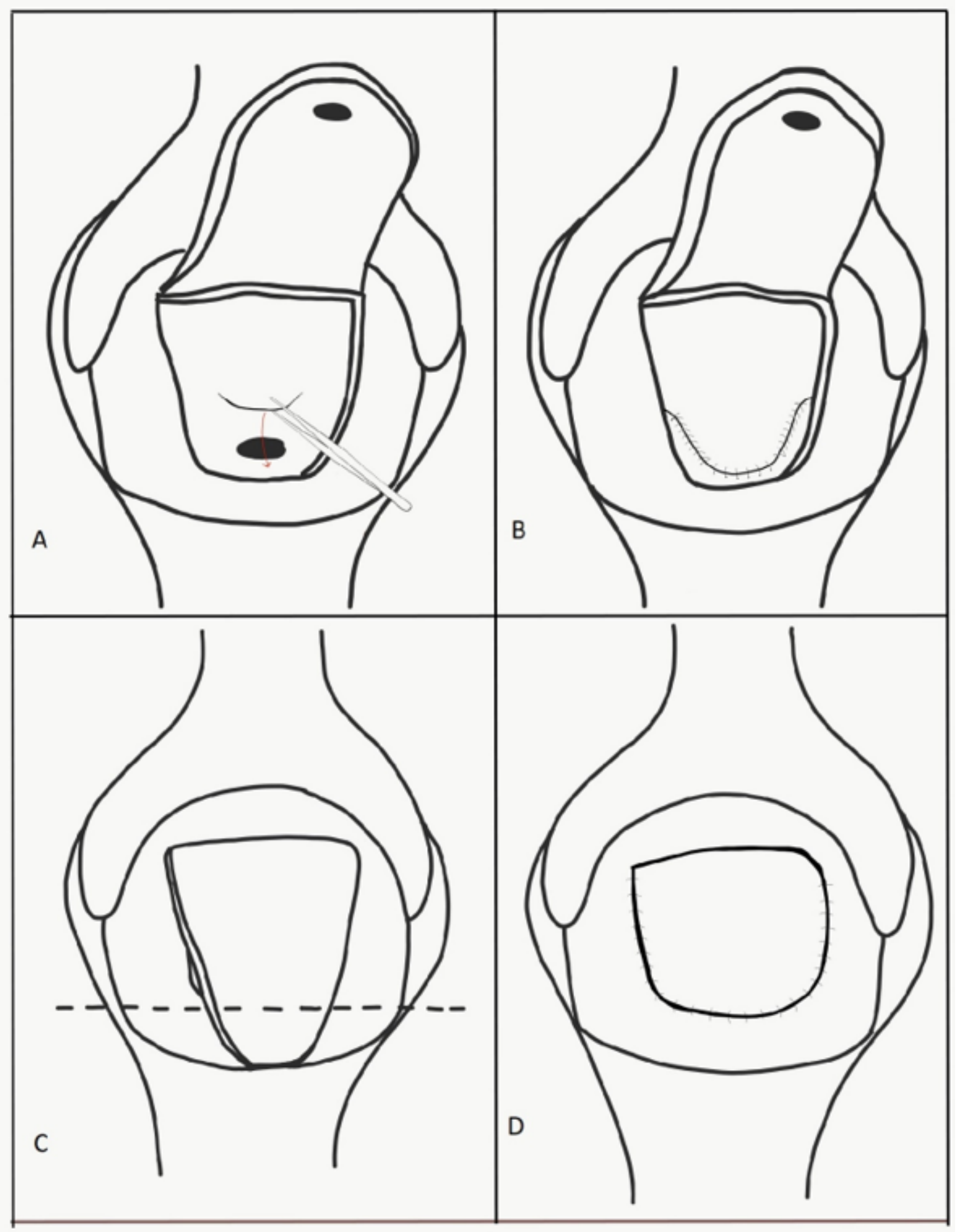

Figure 2

A, B: Internal fistula opening closure in a transverse fashion. C, D: Flap closure. 


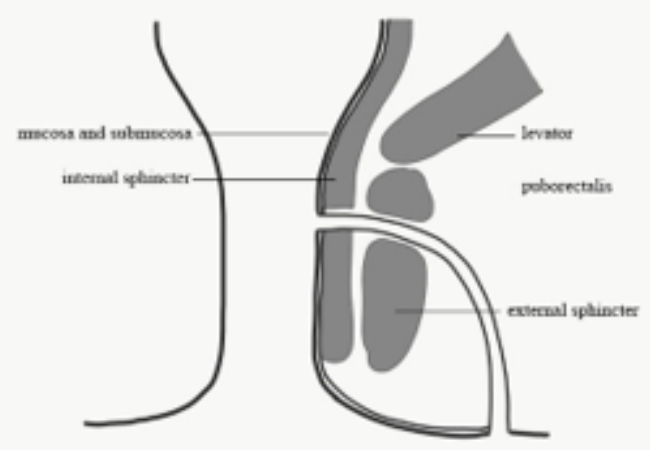

A

\section{Figure 3}

A, B, C: Internal fistula opening and flap closure. (Sagittal view)

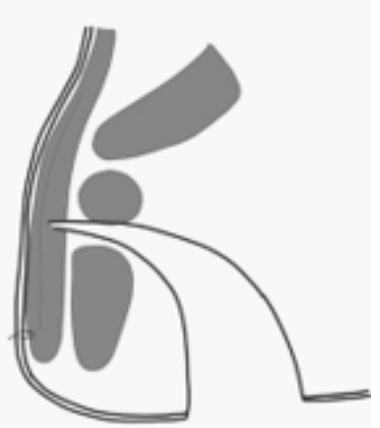

C
B

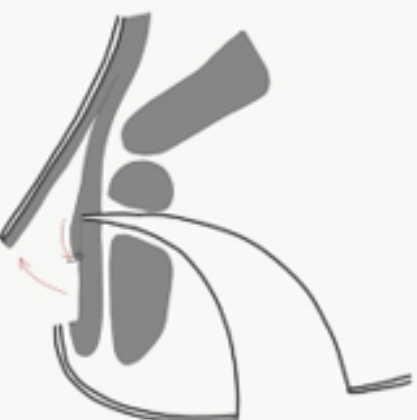

